\title{
The effect of Hylocereus polyrhizus (red dragon fruit) on whole gut transit time of young Malaysian adults
}

\author{
Lim Kean Ghee ${ }^{1}$ \& Ling Chian Voon ${ }^{2 *}$ \\ ${ }^{1}$ Department of Surgery, Clinical Campus, International Medical University, \\ Seremban, Negeri Sembilan, Malaysia; ${ }^{2}$ School of Medicine, International Medical \\ University, Seremban, Negeri Sembilan, Malaysia
}

\begin{abstract}
Introduction: The red dragon fruit (Hylocereus polyrhizus) is a popular fruit, not only where it originated from, in Central America, but across the world including in Asia. It contains healthy minerals, vitamins and antioxidants, and has been shown to have gut motility action in animals. Methods: To determine the effect of red dragon fruit on whole gut transit time, a cross-sectional study of whole gut transit time using two different stool markers was conducted among 128 young Malaysian adults. Results: Red dragon fruit, in a half fruit serving of $225 \pm 25$ grams, reduced mean whole gut transit time from $26.0 \pm 12.9$ hours to $21.9 \pm 12.8$ hours $(p<0.001)$ when colour change in stools was used as an indicator. The tests also showed that $14.8-17.3 \%$ of individuals had whole gut transit time $\geq 40$ hours with carbon as a stool marker compared to only $7.8-8.6 \%$ when red dragon fruit was consumed and used as a marker. Conclusion: This study demonstrated a laxative effect of red dragon fruit among young adults.
\end{abstract}

Keywords: Hylocereus polyrhizus, laxative, whole gut transit time, young adult

\section{INTRODUCTION}

Hylocereus polyrhizus or Hylocereus costaricensis is a tropical fruit with vibrant red skin and sweet, seedspeckled magenta pulp. It originated from Central America where it is known as pitaya and is a member of the cactus family. It is now widely grown in Asia where it is commonly known as red dragon fruit (RDF), on account of its scaly skin. A similar fruit, Hylocereus undatus, the white fleshed dragon fruit, is also popular. Besides its carbohydrate and fibre content, the fruit contains iron, potassium, magnesium, vitamins A and C (Ariffin et al., 2009). In addition, it contains betacyanins and polyphenols which have beneficial antioxidant properties (Ding et al., 2009). The tiny black seeds which are swallowed with the flesh contain essential fatty acids (Ariffin et al., 2009). The red colour of its flesh is derived from betacyanin, which colours stools a visible reddish tinge and the urine also when taken in excessive amounts (Ding et al., 2009).

Animal studies have found that Hylocereus polyrhizus modulates gut microbiota and has an effect on gut motility in mice (Song et al., 2016; Khuituan et al., 2019). This effect of RDF is of interest because laxatives and healthy agents to improve human bowel function are in constant demand. It has been estimated that up to $16 \%$ of the population complains of constipation

\footnotetext{
*Corresponding author: Dr Ling Chian Voon

School of Medicine, International Medical University, Seremban, Negeri Sembilan, Malaysia E-mail: someone.ling13@gmail.com 
and it accounts for 2.5 million physician office visits annually in the United States (Sharma et al., 2017). Constipation consists of a constellation of symptoms including excessive straining, prolonged attempts to defecate, and stools of hard consistency. Primary or functional constipation is not only a disease itself, but straining at stools and hard stools also bring on perianal diseases such as anal fissures, haemorrhoids, and anorectal abscesses (Merchea et al., 2016; Nugent et al., 2018).

And yet, there has not been widespread adoption of objective clinical measurements of bowel habits, not least because even medical practitioners find probing into bowel habits distasteful. Whole gut transit time (WGTT) is one objective measure. It can be measured using wireless capsules, radiopaque markers or more simply, ingestion of a dye (Lee et al., 2014; Kumar et al., 1987; Waller et al., 2011; Séverine et al., 2001). The normal WGTT ranges between 1073 hours (Lee et al., 2014). As a measure to study the practical effect of RDF on bowel action, we examined the WGTT of healthy young adults sampled from students at the International Medical University, Seremban, Malaysia.

\section{MATERIALS AND METHODS}

\section{Ethical approval}

Ethical clearance was obtained from the International Medical University Joint Committee (CSc-Sem6-(12)2018). The authors were accountable for all aspects of work to ensure the accuracy or integrity of any part of the work.

\section{Study design and sampling}

In this cross-sectional study, 128 young adults aged 20-24 years old in a medical school were conveniently sampled to fulfil the minimum number of the required sample size calculated (Charan $\&$ Biswas, 2013). The volunteers accounted for 38\% of the student population in the campus. Pregnant females and individuals on medication were excluded in this study. Demographic data were also collected in a self-administered questionnaire. This study acquired ethical approval and written consent was obtained from the participants.

\section{Whole gut transit measurement}

Two measuring tools were selected in this study - carbon, in activated charcoal tablets, and Hylocereus polyrhizus, RDF itself. A pilot test among five volunteers showed that both tools demonstrated changes in stool appearance after consumption, which was easily detected when the subject was informed on what to look for. All subjects underwent four test rounds. On two occasions, subjects were asked to consume six $250 \mathrm{mg}$ tablets of activated charcoal (1.5gm) within 1 hour of passing motion and to take note when they had stool colour change. After that, on two more occasions, they consumed half of one RDF, which amounted to $225 \pm 25$ grams, within one hour of passing motion. The measurement of whole gut transit time was determined by documenting the times starting with the intake of the measuring tool and ending with positive stool changes. There was an interval of one week between tests with carbon and $\mathrm{RDF}$.

\section{Categorising}

In addition to recording the duration of WGTT, in hours, we also grouped the results into two categories $1<40$ hours and $\geq 40$ hours). WGTT consistency was grouped for each measuring tool (activated charcoal tablets/RDF), with the same WGTT category within the same measuring tool indicating a consistent WGTT. Most western-based studies suggested 30-40 hours as normal mean colonic transit time (Kim \& Rhee, 2012). 
In this study, 40 hours was selected as the cut-off for short and long WGTT among subjects. It is common practice for most people to open their bowels at about the same time each day. It can therefore be expected that WGTT would cluster at 24 hours and 48 hours or multiples of the hours of a day (Séverine et al., 2001). The use of 40 hours allows for individuals from 'up to four hours late one day' and 'four hours early the next' to be captured in the latter group.

\section{Data analysis}

The analysis of data was performed with SPSS 25. The tests included Mann-Whitney test for non-parametric data and Pearson's Chi-square test for categorical data.

\section{RESULTS}

The mean age of the participants was $22.7 \pm 1.1$ years. There were $80(62.5 \%)$ females and 48 males included in this study. They consisted of 75 (58.6\%) Chinese, 33 (25.8\%) Indians, 16 (12.5\%) Malays and 4 (3.1\%) of other races. Figure 1 shows the box plots of four attempts to measure the WGTT of the 128 volunteers. The means of the two attempts with carbon were $26.0 \pm 13.6$ hours and $26.3 \pm 12.1$ hours, which showed no significant difference $(p=0.787)$. Mean

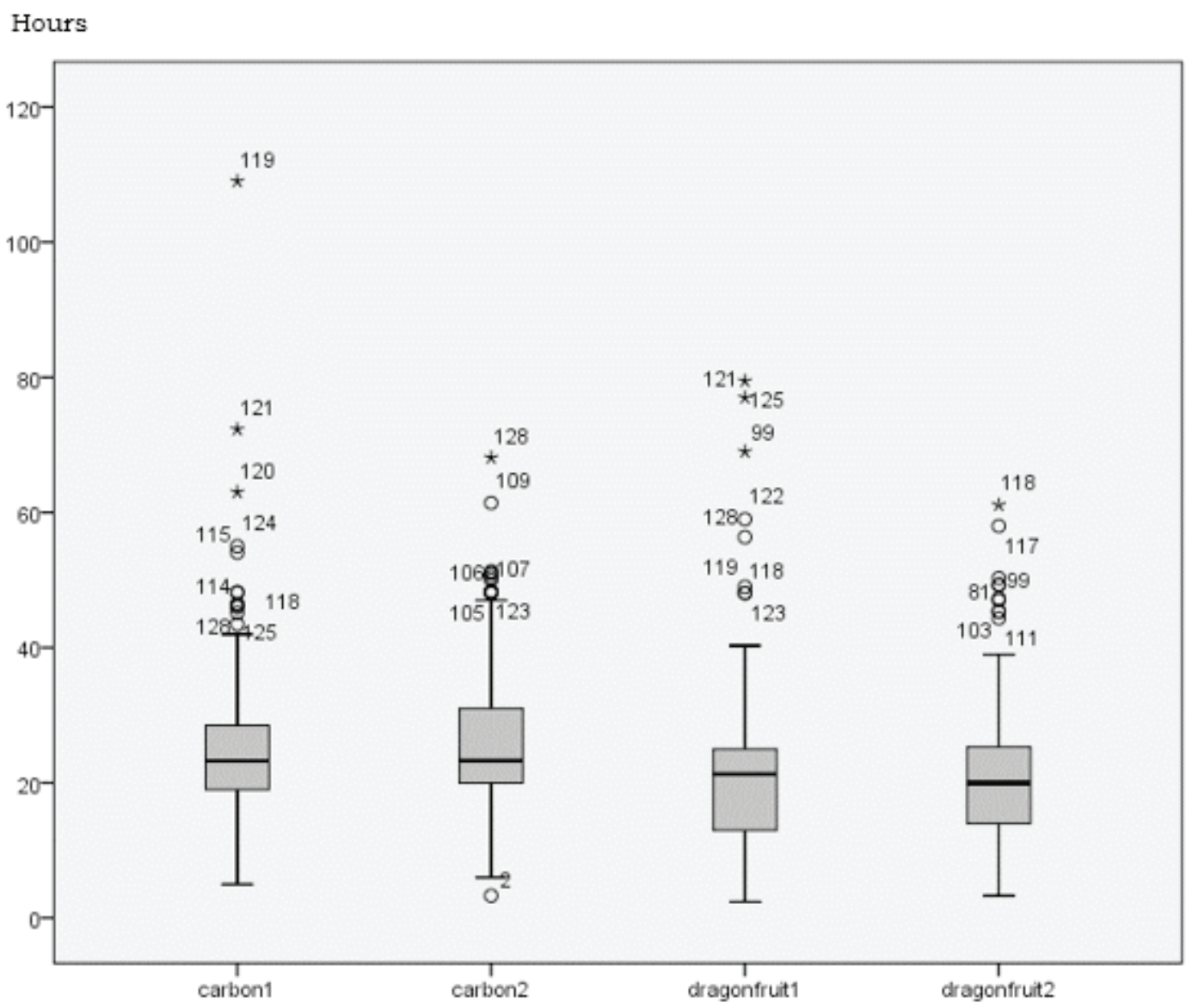

Figure 1. Whole gut transit time for young adults on two occasions using carbon and two occasions using RDF as indicator 
Table 1. Number of subjects having short ( $<40$ hours) and long ( $\geq 40$ hours) WGTT with carbon and RDF

\begin{tabular}{|c|c|c|c|c|}
\hline WGTT & $<40$ hours & $\geq 40$ hours & $\begin{array}{c}<40 \text { hours once } \\
\text { and } \\
\geq 40 \text { hours once }\end{array}$ & $\begin{array}{c}\text { Remainder } \\
\text { (not consistent } \\
\text { across the } \\
\text { carbon and RDF } \\
\text { measurement) }\end{array}$ \\
\hline & $n(\%)$ & $n(\%)$ & $n(\%)$ & $n(\%)$ \\
\hline Carbon 1 & $108(84.4 \%)$ & $19(14.8 \%)$ & & \\
\hline Carbon 2 & $105(82.0 \%)$ & $22(17.3 \%)$ & & \\
\hline Consistent (Carbon) & $99(77.3 \%)$ & $13(10.2 \%)$ & $15(11.7 \%)$ & \\
\hline $\mathrm{RDF} 1$ & $114(89.1 \%)$ & $11(8.6 \%)$ & & \\
\hline RDF 2 & $116(90.6 \%)$ & $10(7.8 \%)$ & & \\
\hline Consistent (RDF) & $109(85.2 \%)$ & $5(3.9 \%)$ & $11(8.6 \%)$ & \\
\hline $\begin{array}{l}\text { Consistent always } \\
\text { (Carbon and RDF) }\end{array}$ & $92(74.2 \%)$ & $2(1.6 \%)$ & & $30(23.1 \%)$ \\
\hline
\end{tabular}

WGTT for the two attempts with RDF, $22.6 \pm 13.6$ hours and $21.4 \pm 10.9$ hours, also showed no significant difference $(p=0.319)$. However, the mean WGTT for subjects using carbon as an indicator $(26.0 \pm 12.9$ hours) was significantly different $(p<0.001)$ compared to when $\mathrm{RDF}$ fruit was used as an indicator (21.9 \pm 12.8 hours).

Table 1 shows the number of individuals with short (40 hours) and long ( $\geq 40$ hours) WGTT. WGTT was short for $82-90 \%$ of individuals during each of the occasions when it was measured. The laxative effect of RDF can be noted in that $14.8-17.3 \%$ of individuals had WGTT $\geq 40$ hours compared to only 7.8 8.6\% with RDF. Grouping also allowed us to note how many individuals were not consistent in the same group. This inconsistent group was $11.7 \%$ for carbon and $8.6 \%$ when consuming RDF. A total of $74.2 \%$ subjects had short WGTT constantly.

\section{DISCUSSION}

A fairly high proportion of young adults $(74.2 \%)$ had a short bowel transit time constantly over four occasions, which appears to be a healthy habit to have.
However, as the box plot showed, there were outliers with WGTT of over 120 hours (hence the data was nonparametric and required the MannWhitney test). These were individuals in which constipation, where there is associated hard stools and straining, was likely to occur. In addition, there were individuals who were not regularly long or short in their WGTT. Repeated measures of WGTT helped identify these individuals appropriately.

\section{Effect of RDF on WGTT}

It was clear that RDF had a laxative effect. It reduced mean WGTT by 4.2 hours. It reduced WGTT from $\geq 40$ hours to $<40$ hours for $22(17.2 \%)$ of the subjects at least once. On the other hand, in three individuals who had short WGTT with carbon, their WGTT was $\geq 40$ hours once with RDF and in one person, it was associated with long WGTT twice. As with any laxative agent, the effect is not perfectly consistent as other factors and events in the life of an individual affects his/her bowel movement.

Khuituan et al. (2019) has shown that dragon fruit oligosaccharides reduced total gut transit time by $30 \%$ in 
mice. The experiment revealed dragon fruit oligosaccharides to have bulkforming effects and increased colonic smooth muscle contractions in mice. The studied mice did not show any morphological changes in their colonic mucosa or muscular layer after two weeks of consistent feeding with dragon fruit oligosaccharides at $500 \mathrm{mg} / \mathrm{kg}$ (Khuituan et al., 2019). This gave us reassurance that the laxative effect of $\mathrm{RDF}$ is healthy and there is no evidence to suggest that it is harmful. No subjects in our study reported any untoward effects. Oligosaccharides in dragon fruit demonstrated additional beneficiary effects on animal model in various studies. Peerakietkhajorn et al. (2020)'s study demonstrated that dragon fruit oligosaccharides increased the probiotics population (Bifidobacteria, Lactobacilli) in proximal and distal colon of mice. Furthermore, Pansai et al. (2019) found immune boosting properties of prebiotic dragon fruit oligosaccharides in animal model.

\section{Limitations}

Activated charcoal tablets are generally inert in regards to WGTT, but may rarely cause delayed bowel motion (Chyka et al., 2005). We have not investigated the diet of our subjects, and as we know, dietary differences may affect WGTT. However, this factor may be nearly impossible to control for even with a regimented diet. Nevertheless, most Malaysians share much in common in their diet, especially our group of students who were based in the same campus.

Our measure of WGTT depended on subjects' reporting about when they observed a colour change and this relied on the co-operation of the subjects. Therefore, we cannot ascertain if they have identified the colour change accurately.

\section{Strengths}

We achieved a high response rate with data from 128 subjects and complete data in 125 subjects. Our sample population of students shared many similarities and common features in their environment, which controlled for factors that may have influenced WGTT measurements such as different activities, lifestyle and weather, that is known to influence hydration. In addition, not regimenting the diet of our subjects showed us the real effect RDF had among individuals in their daily life. Bowel habit varied dayto-day in all individuals and repeated measurements to obtain a mean was an advantage.

\section{CONCLUSION}

This study revealed a laxative effect of red dragon fruit among young adults. Further large scale, randomised controlled trials are needed to study the potential usage of dragon fruit as a dietary modification in constipationrelated disorders.

\section{Acknowledgement}

We were fortunate to have the support from volunteers Heyman Raj Bari, Lai Kah Jing, Lye Xin Yi, and Jhanani Arjunan who contributed their time and effort in collecting the data.

\section{Authors' contributions}

LKG, principal investigator, conceptualised and designed the study, conducted data analysis and interpretation, prepared the draft of the manuscript and reviewed the manuscript; LCV, conducted data collection, assisted in drafting of the manuscript, reviewed the manuscript.

\section{Conflict of interest}

We declare that we have no potential financial and non-financial conflicts of interest in the subject matter or materials discussed in this manuscript.

\section{References}

Ariffin A, Bakar J, Tan CP, Rahman RA, Karim R \& Loi CC (2009). Essential fatty acids of pitaya (dragon fruit) seed oil. Food Chem 114(2):561564. 
Charan J \& Biswas T (2013). How to calculate sample size for different study designs in medical research? Indian $J$ Psychol Med 35(2):121-126.

Chyka PA, Seger D, Krenzelok EP \& Vale JA (2005). American Academy of Clinical Toxicology, European Association of Poisons Centres and Clinical Toxicologists. Position paper: Singledose activated charcoal. Clin Toxicol Phila $\mathrm{Pa}$ 43(2):61-68

Ding P, Koi Chew M, Abdul Aziz S \& Lai O (2009). Red-fleshed pitaya (Hylocereus polyrhizus) fruit colour and betacyanin content depend on maturity. Int Food Res $J$ 16:233-242.

Khuituan P, K-da S, Bannob K, Hayeeawaema F, Peerakietkhajorn S, Tipbunjong C, Wichienchot S \& Charoenphandhu N (2019). Prebiotic oligosaccharides from dragon fruits alter gut motility in mice. Biomed Pharmacother 114:108821.

Kim ER \& Rhee PL (2012). How to interpret a functional or motility test - colon transit study. $J$ Neurogastroenterol Motil 18(1):94-99.

Kumar A, Kumar N, Vij JC, Sarin SK \& Anand BS (1987). Optimum dosage of ispaghula husk in patients with irritable bowel syndrome: correlation of symptom relief with whole gut transit time and stool weight. Gut 28(2):150155.

Lee YY, Erdogan A \& Rao SSC (2014). How to Assess Regional and Whole Gut Transit Time with Wireless Motility Capsule. J Neurogastroenterol Moti. 20(2):265-270.

Merchea A \& Larson DW (2016). Anus. In CM Townsend, RD Beauchamp, BM Evers \& KL Mattox (Eds.). Sabiston Textbook of Surgery 20th Edition (pp.1394-1417). Elsevier, Philadelphia.
Nugent K (2018). The anus and anal canal. In NS Williams, PR O'Connell, AW Mc Caskie (Eds.). Bailey \& Love's Short Practice of Surgery 27th Edition. Bailey CRC Press, Boca Raton (pp. 1339-73).

Pansai N, Chakree K, Chutha TY, Raungrut P, Yanyiam N \& Wichiencho S (2019). Gut Microbiota Modulation and Immune Boosting Properties of Prebiotic Dragon Fruit Oligosaccharides. IJFST. 55:55-64

Peerakietkhajorn S, Jeanmard N, Chuenpanitkit P, K-da S, Bannob K \& Khuituan P (2020). Effects of plant oligosaccharides derived from dragon fruit on gut microbiota in proximal and distal colon of mice. Sains Malaysiana. 49(3):603-611

Séverine M, Chantal C, Pietro T, Aldo R, Claudio L \& Antoine J (2001). A Fermented Milk with a Bifidobacterium Probiotic Strain DN-173 010 Shortened Oro-Fecal Gut Transit Time in Elderly. Microb Ecol Health Dis 13(4): 217-222.

Song H, Chu Q, Yan F, Yang Y, Han W \& Zheng X (2016). Red pitaya betacyanins protects from diet-induced obesity, liver steatosis and insulin resistance in association with modulation of gut microbiota in mice. $J$ Gastroenterol Hepatol 31(8):1462-1469.

Sharma A \& Rao S (2017). Constipation: Pathophysiology and Current Therapeutic Approaches. Handb Exp Pharmacol 239:59-74.

Waller PA, Gopal PK, Leyer GJ, Ouwehand AC, Reifer C, Stewart ME \& Miller LE (2011). Doseresponse effect of Bifidobacterium lactis HNO19 on whole gut transit time and functional gastrointestinal symptoms in adults. Scand $J$ Gastroenterol 46(9):1057-1064. 